\title{
Causes and consequences of fetal growth retardation in pigs
}

\author{
C. J. Ashworth ${ }^{1}$, A. M. Finch ${ }^{2}$, K. R. Page ${ }^{3}$, M. O. Nwagwu ${ }^{1}$ \\ and H. J. McArdle 2 \\ 'Animal Biology Division, SAC, Craibstone Estate, Bucksburn, Aberdeen AB21 9YA, UK; \\ ${ }^{2}$ Division of Integrative and Developmental Biology, Rowett Research Institute, Bucksburn, \\ Aberdeen AB21 9SB, UK; and ${ }^{3}$ Department of Biomedical Sciences, University of Aberdeen, \\ Aberdeen AB24 3FX, UK
}

In pigs, as in other species, fetal growth retardation is associated with reduced birth weight and increased risk of fetal and neonatal death. As there are few opportunities after birth to remedy the detrimental effects of low birth weight, it is important to understand both the intrinsic and extrinsic factors associated with inadequate fetal growth and to determine when growth retarded fetuses deviate from the growth trajectory of their normal sized littermates. Inadequately grown pig fetuses can be identified statistically as early as day 30 of the 114 days of gestation, indicating that limited uterine space is not a primary determinant of fetal growth. Comparisons of the smallest fetus within a litter with a normal sized sibling reveal that inadequately grown fetuses have altered endocrine status and lower circulating concentrations of many essential amino acids. In addition, the placenta supplying the smallest fetus is disproportionately small and has a reduced capacity to transport amino acids. Understanding the timing and the causes of fetal growth retardation in pigs may help us to devise appropriate strategies to reduce the incidence and hence the detrimental postnatal consequences of runting.

\section{Nature, timing and prevalence of fetal growth retardation}

Piglet birth weights are the major determinant of subsequent survival and total weaning weights of the litter (Winters et al., 1947). However, many litters contain at least one piglet that is significantly lighter than its littermates. In most cases, the piglet with low birth weight is an example of fetal growth retardation in the absence of obvious causes such as fetal anomaly or maternal illness. Low birth weight may be due to an intrinsic failure of fetal growth or arise as a consequence of inadequate placental function.

Several definitions have been used to identify inadequately grown fetuses within a litter. These include fetuses or neonates weighing less than two standard deviations below the mean body weight for gestational age, those weighing less than the tenth percentile (Bauer et al., 1998), the smallest of each litter, those weighing less than two-thirds of the mean weight of the uterine horn, fetuses in the middle of the horn and those shown to be outliers in an otherwise 
normally distributed population (Royston et al., 1982; van der Lende et al., 1990). Various terms including intrauterine growth retardation (IUGR), small for gestational age (SGA) and runt have been used to refer to piglets with low birth weights.

Clinical studies distinguish infants with low birth weight as either SGA or IUGR. SGA babies, usually defined as those weighing less than the tenth percentile at birth, are considered to have achieved their genetic potential for intrauterine growth and exhibit normal allometry. In contrast, IUGR infants do not achieve their normal intrauterine growth potential and exhibit asymmetrical growth characterized by normal brain growth at the expense of the growth of internal organs such as the liver and kidney. Similarly, in pigs, fetal growth restriction is characterized by asymmetrical organ growth, as demonstrated by differences in allometric coefficients for fetal liver, heart and lungs (Da Silva et al., 2000). Widdowson (1971) suggested that such differences in relative organ size might arise as a consequence of hyperplasia rather than hypertrophy.

It is of interest that the within-litter distribution in piglet birth weight appears to be established by the end of the first month of pregnancy (Perry and Rowell, 1969; van der Lende et al., 1990; Wise et al., 1997). Furthermore, statistical assessment of the time at which growth-retarded fetuses first deviate from the growth trajectory of their normally grown siblings indicates that runting is apparent by day 44 of pregnancy (Cooper et al., 1978). By plotting the cumulative probability of fetal weights within a litter, it is possible to distinguish small fetuses forming part of a normally distributed population from those lying outside an otherwise normally distributed population (Finch et al., 1999; Fig. 1). Using this approach, we have confirmed that inadequately grown pig fetuses can be identified as early as day 30 of pregnancy and that the prevalence of inadequately grown fetuses does not increase between day 30 and parturition. This finding indicates that inadequate uterine space is not a major factor contributing to poor growth of pig fetuses. Instead, fetal growth may be related to the ability of the placenta to deliver nutrients. Indeed, placental mass on day 29 of pregnancy is an accurate determinant of fetal weight in late gestation (Knight et al., 1977).

\section{Possible causal factors of fetal growth retardation}

\section{Genotype}

Meishan pigs give birth to a mean of four more live piglets per litter than do contemporary gilts or sows from indigenous breeds. This increase is achieved through a higher prenatal survival, which in late pregnancy is accommodated through limited fetal growth and reduced within-litter variability in fetal size (Lee and Haley, 1995).

Reciprocal embryo transfer between indigenous Landrace $\times$ Large White gilts and Chinese Meishan gilts demonstrated clearly that maternal genotype has a major influence on fetal size (Ashworth et al., 1990). Day 30 fetuses carried by Meishan mothers were significantly lighter than fetuses carried by Landrace $\times$ Large White recipients, regardless of the genotype of the donor gilt. In this experiment, maternal genotype accounted for $>70 \%$ of the variation in fetal weight on day 30 of pregnancy. This is similar to the situation observed at term. Crossbreeding trials have shown that the $20-25 \%$ difference between the birth weight of Meishan and Large White piglets is almost entirely due to the maternal genotype and is explained only partially by differences in litter size per se (Lee and Haley, 1995). This finding indicates that the Meishan maternal environment may limit fetal growth.

Although placentae supplying Meishan fetuses are more vascular (Ashworth et al., 1998a; Biensen et al., 1999a), have a greater surface area (Ashworth et al., 1998a) and secrete more protein in vitro (C. J. Ashworth and L. Beattie, unpublished) than do placentae from 

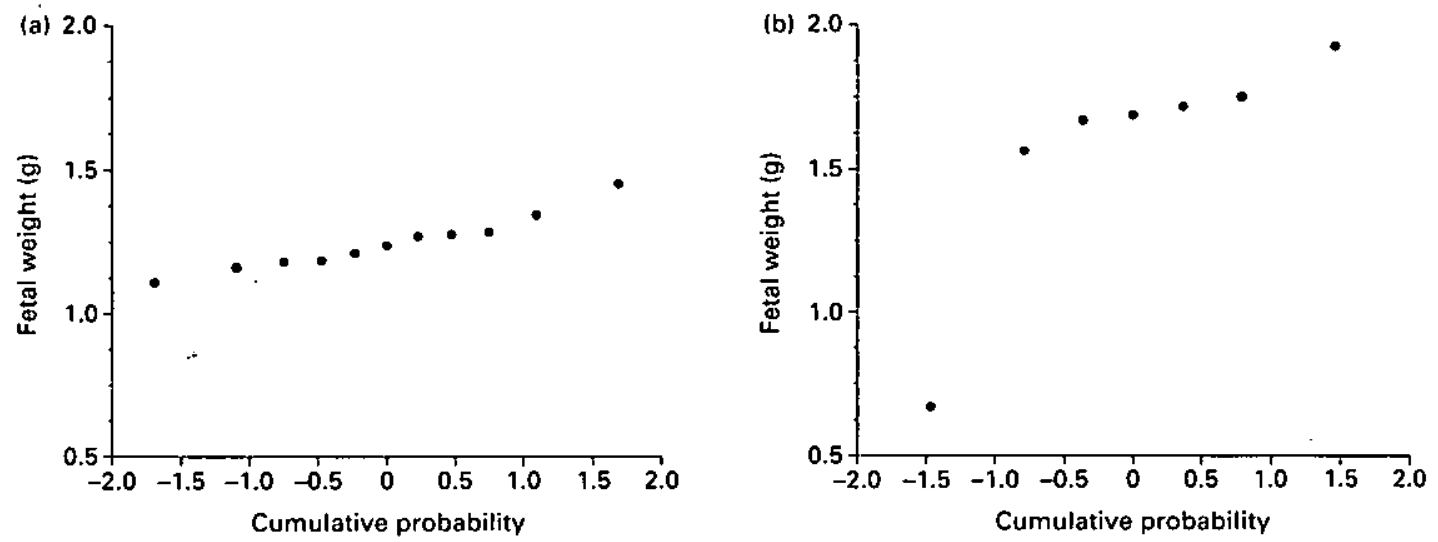

Fig. 1. Cumulative probability plots showing the within-litter range in pig fetal weights on day 30 of - pregnancy. (a) Small for gestational age (SCA) fetuses are lighter than their littermates, but form part of a normally distributed population. (b) Intrauterine growth retarded (IUGR) fetuses lie outside an otherwise normally distributed population.

indigenous breeds, Meishan placentae are disproportionately lighter. Ford (1997) reported that the fetal weight:placental mass ratio was $8.7 \pm 0.4$ for Meishan conceptuses and $3.4 \pm$ 0.8 for conceptuses from the control breed. The reason for this difference is unclear, but may be related to differences in the mitogenic potential of fetal fluids from different breeds. Allantoic fluid collected from Meishan gilts on day 100 of pregnancy was associated with a reduction in the proliferation of placental cells in vitro (Ashworth et al., 1998b), whereas allantoic fluids from Large White $\times$ Landrace gilts did not alter proliferation of placental cells. The nature of the anti-proliferative agent in allantoic fluids from Meishan pigs remains to be determined, but it does not appear to involve cytokine tumour necrosis factor $\alpha$ (TNF- $\alpha$ ) (C. ). Ashworth and $M$. Ewen, unpublished), which has been implicated in the regulation of placental growth in other species.

Both fetal insulin and thyroid hormones stimulate fetal growth by increasing the mitotic drive and nutrient availability for tissue accretion. Although Meishan fetuses are approximately one-third smaller than Large White $\times$ Landrace fetuses, Meishan fetal plasma concentrations of insulin, thyroxin and tri-iodothyronine are higher (Nwagwu et al., 2000). The reason for this surprising finding is unclear. It does not appear to be related to differences in fetal body composition between breeds (M. Nwagwu, L. G. Yang and C. J. Ashworth, unpublished), but may reflect genotype differences in the relationship between fetal endocrinology and growth.

\section{Maternal nutrition}

There have been few comprehensive large-scale studies performed to address the effects of specific nutrients on fetal growth and subsequent litter size. Furthermore, the critical stages of pregnancy at which fetal development is most susceptible to changes in maternal nutrition and the postnatal consequences of inappropriate nutrition during fetal life are poorly understood. Although it is generally accepted that increased feed intake by sows during gestation increases piglet birth weight, this has not been adopted commercially because the increased feed costs outweigh the perceived financial benefits of a modest increase in birth weight. One study in which large numbers $(n=187)$ of pregnant sows were fed diets of 
different energy content for four successive parities (Young et al., 1990) revealed a small increase in piglet birth weight in sows receiving higher dietary energy.

Some of the most interesting data describing the effects of nutritional status on fetal and postnatal development have been generated by feeding gilts or sows on diets deficient in protein. Schoknecht et al. (1993) found that the progeny of sows receiving a restricted protein diet $(0.5 \%(\mathrm{w} / \mathrm{w})$ protein) compared with those receiving a control $(13 \%(\mathrm{w} / \mathrm{w})$ protein) diet in pregnancy had reduced birth weight and growth rates until slaughter. Applying the protein restriction between day 1 and day 44 , or between day 81 and term only, reduced birth weight, but not subsequent daily live weight gain. Other studies have shown that protein deficiency during early or mid-gestation decreases placental and fetal growth (Schoknecht et al., 1994) and changes fetal plasma, amniotic and allantoic fluid amino acid concentrations (Wu et al., 1998).

Of the various specific nutrients that may affect fetal and placental development, the effects of supplementary folic acid are worthy of note. The addition of folic acid (2 p.p.m.) to the diet of gilts for three oestrous cycles before mating and throughout pregnancy increased fetal crown-rump length, weight and both protein and RNA content (Harper et al., 1996), thereby indicating that this nutrient may enhance fetal growth.

\section{Litter size and uterine capacity}

Superficially, it would be expected that as litter size increases, the demand for uterine space and maternal nutrients would also increase, leading to an inverse relationship between litter size and individual piglet birth weight. Whether this relationship holds over a spontaneously occurring range of litter sizes is equivocal. In a study involving 50 litters, Bauer et al. (1998) found a strong inverse correlation between the mean litter weight and litter size. Interestingly, Pere et al. (1997) observed that fetal weight on day 112 of pregnancy was related inversely to litter size on day 35 of pregnancy. This finding may be a reflection of the extent of placental development during early pregnancy, which, in turn, affects subsequent fetal growth.

Uterine capacity has been defined as the maximum number of fetuses that can be carried successfully to term when the number of potentially viable conceptuses is not limiting (Christenson et al., 1987). Treatments imposed to exceed this uterine capacity, including unilateral ovariectomy-hysterectomy or transfer of supraphysiological numbers of embryos, tend to be associated with increased prenatal mortality (Wu et al., 1989), rather than reduced fetal size.

Of particular interest in polytocous species is the naturally occurring variation in fetal size among siblings occupying the same uterus. Comparisons of normally and inadequately grown fetuses and their placentae within the same uterus allow intrinsic factors associated with differential fetal growth to be studied free from the confounding effects of maternal genotype, nutrition and husbandry. The remainder of this review will address the causes and consequences of within-litter variation in fetal size. Some local factors associated with inadequate fetal growth in pigs are highlighted (Fig. 2).

\section{Location in the uterus}

Within the normal range of litter sizes, the distribution and spacing of fetuses are not uniform throughout the length of the uterus. After a study of $>400$ pregnant pigs, Dziuk (1985) reported that on day 25 the space available to each fetus decreased from the ovarian to the cervical end of the uterine horn. By day 40 , the least space was available in the mid-portion of each horn, with similar space at each end. It may be expected that these differences in uterine space would be reflected in fetal size. However, the data relating position within the uterus and fetal size are equivocal. 


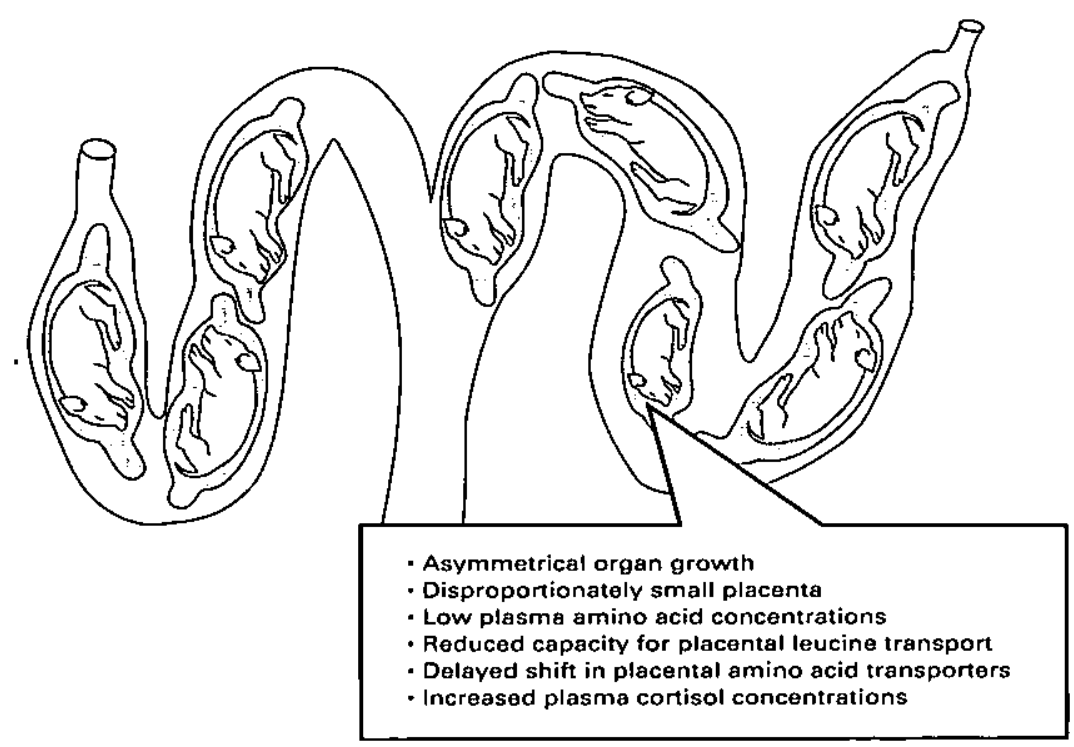

Fig. 2. Schematic diagram showing differently sized pig fetuses in the uterus. The box highlights physiological and biochemical factors associated with the smallest fetus in the uterus.

In a study using 348 gilts, Wise et al. (1997) found no relationship between fetal weight and uterine position on day 30; however, on days 70 and 104 of pregnancy, the heavier fetuses were found at the ovarian ends and light fetuses at the cervical ends of the uterine horns. In contrast, Perry and Rowell (1969) found that fetuses at either end of the uterine horn tended to be larger compared with those in the mid-portion. It is often assumed that the mid-portion of the uterine horn may represent a disadvantaged site, because of increased competition for space or reduced arterial supply. However, Perry and Rowell (1969) found no relationship between fetal size and uterine vascular architecture. Most descriptions of the relationship between uterine position and fetal size are confounded by the litter size or by the number of fetuses in each uterine horn. The formula used to calculate relative uterine position described by Ashworth (1991), which expresses the position of each fetus within the uterine lumen on a uniform scale from 0 (ovarian) to 1 (cervical), overcomes this problem. When this formula is applied, there is no evidence that a particular position in the uterine horn is associated with advantages for fetal growth (A. M. Finch, P. F. N. Da Silva and C. J. Ashworth, unpublished; Fig. 3).

\section{Fetal sex}

From at least day 70 of pregnancy, male pig fetuses and their associated placentae are heavier than female fetuses and placentae (Wise and Christenson, 1992). These authors also presented data indicating that in late pregnancy (day 104) the sex of neighbouring fetuses within the uterus affected fetal size. Specifically, they reported that a fetus with both neighbours of the opposite sex was lighter than a fetus surrounded by neighbours of the same sex and proposed that fetuses with neighbours of the opposite sex may make up most of the piglets with low birth weight. As expected, plasma concentrations of the anabolic steroid testosterone were higher in male fetuses, but, in contrast to the situation in mice (vom Saal 


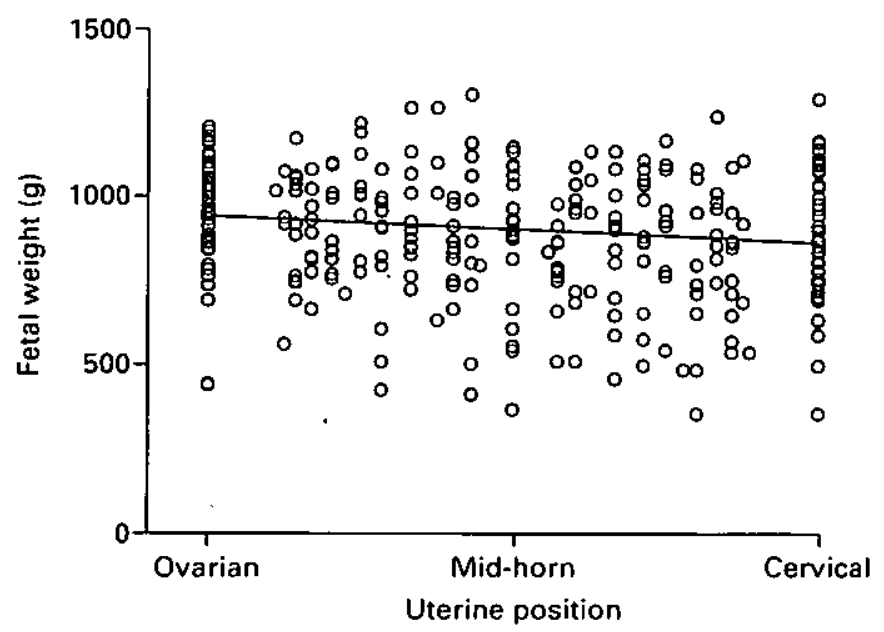

Fig. 3. Relationship between pig fetal weight and uterine location on day 100 of pregnancy. The position of each fetus within the uterine lumen was expressed on a uniform scale (uterine position) from 0 (ovarian) to 1 (cervical) ((fetal number - 1)/(total number in horn -1$)$ ). The graph shows data from 305 fetuses obtained from 24 litters. $R^{2}=0.019$. (A. M. Finch, P. F. N. Da Silva and C. J. Ashworth, unpublished).

et al., 1990), female pig fetuses with two male neighbours did not have altered testosterone concentrations. Our preliminary data (C. J. Ashworth and H. J. McArdle, unpublished) also indicate that the sex of neighbouring fetuses can affect relative organ size, with positive relationships observed between relative liver mass and number of male neighbours in day 100 female fetuses.

\section{Placental nutrient transport}

The efficiency with which the placenta transports nutrients and oxygen to the fetus is determined by its surface area of contact with the uterine wall (chorionic villus surface area) and by blood flow at the maternal-fetal interface, and depends on transplacental transport kinetics and transporters. Pigs have a non-invasive diffuse epitheliochorial placenta in which the maternal blood supply is well separated from the absorptive surface of the chorion. The rate of oxygen transport is limited by placental blood flow. In contrast, the abundance and activity of specific transport proteins regulate placental transport of glucose, amino acids, ions and molecules. Placental glucose transport occurs by facilitated diffusion involving several glucose transporter (GLUT) protein isoforms. Many amino acids taken up by the placenta are transported against a feto-maternal concentration gradient by energy-dependent mechanisms. In pigs, as in other species, these include several sodium-dependent and sodiumindependent amino acid transporter systems that have different levels of activity. Classically, amino acid transporters have been classified alphabetically according to their preferred substrates, with sodium-independent transporters having lower case letters and sodiumdependent transporters uppercase letters (Fig. 4).

Placentae supplying the smallest fetus in the uterus are disproportionately lighter than those supplying larger fetuses in the same litter (Ashworth and McArdle, 1999) (Table 1). This 


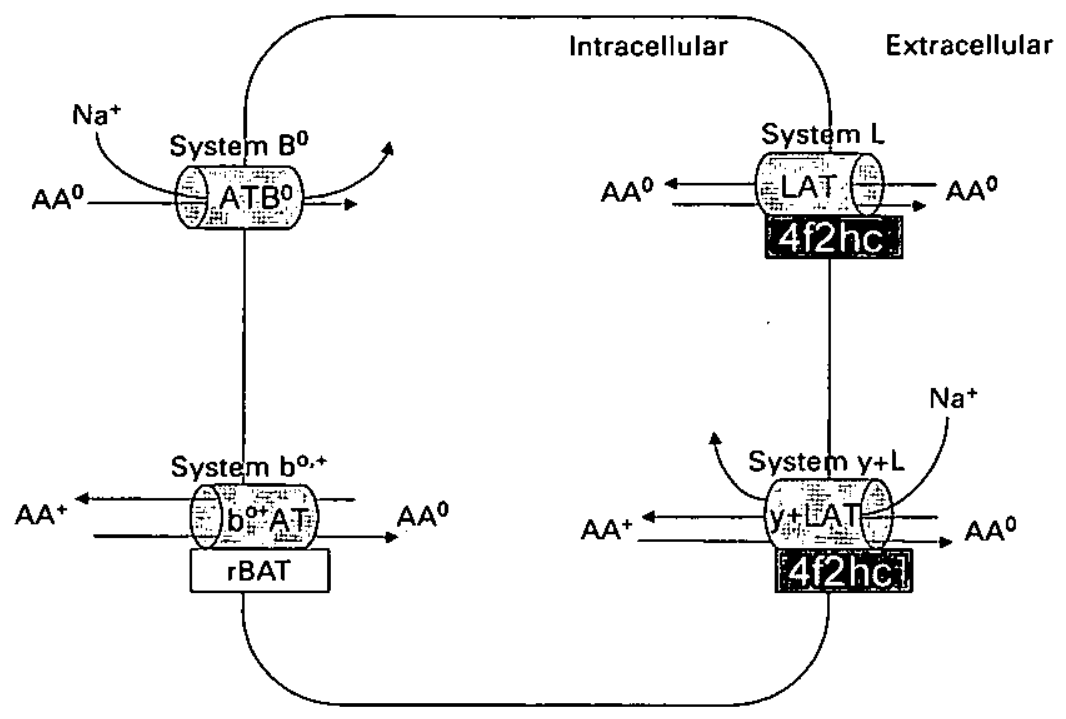

Fig. 4. Schematic diagram of amino acid transport systems. System L. exchanges neutral amino acids, whereas sodium-dependent system $y+L$ and sodiumindependent system $b^{0,+}$ exchange cationic amino acids and neutral amino acids. These members of the glycoprotein-associated amino acid transporter family are heterodimeric in nature, with heavy chains (4f2hc/rBAT) and light chains (LAT, $\left.y+L A T, b^{0+} A T\right)$. Sodium-dependent system $B^{0}$ transports neutral amino acids. $A A^{+*}$ cationic amino acids; $\mathrm{AA}^{0}$, neutral amino acids.

observation, combined with the positive relationship between placental blood flow and fetal weight (Wootton et al., 1977), implies that there is a generalized reduction in the ability of placentae supplying small fetuses to deliver nutrients.

There is increasing evidence in a variety of species, including rats, guinea-pigs, sheep and humans, of an association between placental amino acid transport and fetal growth (for review see Sibley et al., 1997). Direct evidence that placental amino acid transport is defective came from in vivo studies in sheep in which ${ }^{13} \mathrm{C}$-labelled leucine was infused during late (days 117-128) pregnancy (Ross et al., 1996). Maternal leucine flux into the placenta supplying the growth-retarded fetus was reduced markedly. This finding, coupled with lower concentrations of several essential amino acids in fetal plasma obtained from growth-retarded pig fetuses (Ashworth and McArdle, 1999), indicates that the capacity of pig placentae to transport amino acids to the fetus may be associated with fetal growth.

Using membrane vesicles produced from pig chorioallantoic membrane, Ashworth and McArdle (1999) demonstrated that placentae supplying inadequately grown fetuses have a reduced capacity to transport the essential amino acid leucine. Leucine uptake is inhibited by 2-amino-2-norbornane-carboxylic acid, indicating that transport occurs via the system $\mathrm{L}$ amino acid transporter system. The reliance on sodium-dependent amino acid transport systems changes during gestation. These gestational changes in the nature of leucine uptake differ between placentae supplying normally and inadequately grown pig fetuses (Finch et al., 2000; Fig. 5). On days 45 and 65 of pregnancy leucine uptake occurs predominantly by sodium-independent channels. By day 100 of pregnancy, placental leucine uptake to normally grown fetuses involves both sodium-dependent and sodium-independent transport. 
Table 1. Weight of the smallest and normal sized pig fetuses and mass of their placentae on days 45,65 and 100 of pregnancy

\begin{tabular}{|c|c|c|c|c|c|c|c|}
\hline \multirow[b]{2}{*}{ Day } & \multirow[b]{2}{*}{$n$} & \multicolumn{3}{|c|}{ Normal sized fetus } & \multicolumn{3}{|c|}{ Smallest fetus } \\
\hline & & $\begin{array}{c}\text { Fetal weight } \\
\text { (g) }\end{array}$ & $\begin{array}{l}\text { Placental } \\
\text { mass } \\
\text { (g) }\end{array}$ & $\begin{array}{c}\text { Placental } \\
\text { mass:fetal } \\
\text { weight }\end{array}$ & $\begin{array}{l}\text { Fetal } \\
\text { weight } \\
\text { (g) }\end{array}$ & $\begin{array}{l}\text { Placental } \\
\text { mass } \\
\text { (g) }\end{array}$ & $\begin{array}{c}\text { Placental } \\
\text { mass:fetal } \\
\text { weight }\end{array}$ \\
\hline 45 & 11 & $19.3 \pm 0.6$ & $77.3 \pm 6.9$ & $3.9 \pm 0.3$ & $16.3 \pm 0.7^{* * *}$ & $35.6 \pm 3.8^{* * *}$ & $2.2 \pm 0.2^{* * *}$ \\
\hline 65 & 10 & $199.5 \pm 9.1$ & $145.0 \pm 23.2$ & $0.7 \pm 0.1$ & $146.6 \pm 12.3^{* * *}$ & $69.1 \pm 13.1^{* *}$ & $0.4 \pm 0.1^{* *}$ \\
\hline 100 & 22 & $951.2 \pm 27.4$ & $213.6 \pm 8.6$ & $0.23 \pm 0.01$ & $572.9 \pm 33.2^{* * *}$ & $110.0 \pm 11.5^{* * *}$ & $0.20 \pm 0.02$ \\
\hline
\end{tabular}

$n=$ number of litters.

Values marked with an asterisk are significantly different compared with values from corresponding normal sized fetus; ${ }^{* *} P<0.01,{ }^{* *} P<0.001$ (paired $\mathrm{ftest}$ between smallest and normal sized fetus on each day of pregnancy studied).

This shift in transport systems was not observed in placentae supplying the smallest fetuses, which continue to rely predominantly on sodium-independent transport.

At present, there are no data on the expression of the different transporters in pig placenta and it is not known how the ontogeny of expression is related to fetal development. Recent reports have demonstrated the heterodimeric nature of amino acid transporters, in which the transporter consists of a common heavy chain ( $4 \mathrm{f} 2 \mathrm{hc} / \mathrm{rBAT}$ ) bound to different light chains, each conferring different transport characteristics (Deves and Boyd, 2000) (Fig. 4). It is possible that the differences in placental leucine uptake between the placentae supplying small and normal fetuses could result from differences in relative abundance of specific light chains. In the rat placenta, gestational changes in expression of system $y+L$ amino acid transporters, involved in transport of lysine and arginine, correlate with changes in the abundance of $4 \mathrm{f} 2 \mathrm{hc}$ expression. As $4 \mathrm{f} 2 \mathrm{hc}$ is required for the cell surface expression and function of transporter light chains, the decrease in total transport observed in the placentae supplying small fetuses may result from delayed placental development leading to decreased $4 \mathrm{f} 2$ expression.

\section{Endocrine and paracrine factors affecting fetal growth}

Fetal hormones promote growth and development in utero by altering both metabolism and gene expression in fetal tissues. Their effects on growth may be mediated in part by other growth factors such as the insulin-like growth factors (IGFs) and cytokines such as TNF- $\alpha$ and colony stimulating factor 1 (CSF-1). Fetal hormones such as cortisol, thyroxin and insulin help to ensure that fetal growth is commensurate with nutrient supply and that prepartum maturation occurs in preparation for extrauterine life.

The IGFs have metabolic, mitogenic and differentiative activities, all of which play a role in promoting growth before and after birth. In most species, IGF-I concentrations are low during fetal life, and IGF-II plays a more prominent role in fetal growth. Our data show no effect of fetal size on day 100 plasma IGF-II concentrations; however, small fetuses have lower concentrations of both plasma IGF-I on day 100 (Nwagwu et al., 2000) and hepatic IGF binding protein 2 (IGFBP-2) on day 90 (Kampman et al., 1993) compared with normally grown fetuses in the same uterus.

We have observed inverse relationships between fetal weight and both plasma and allantoic fluid cortisol concentrations on day 100 and between fetal weight and plasma 


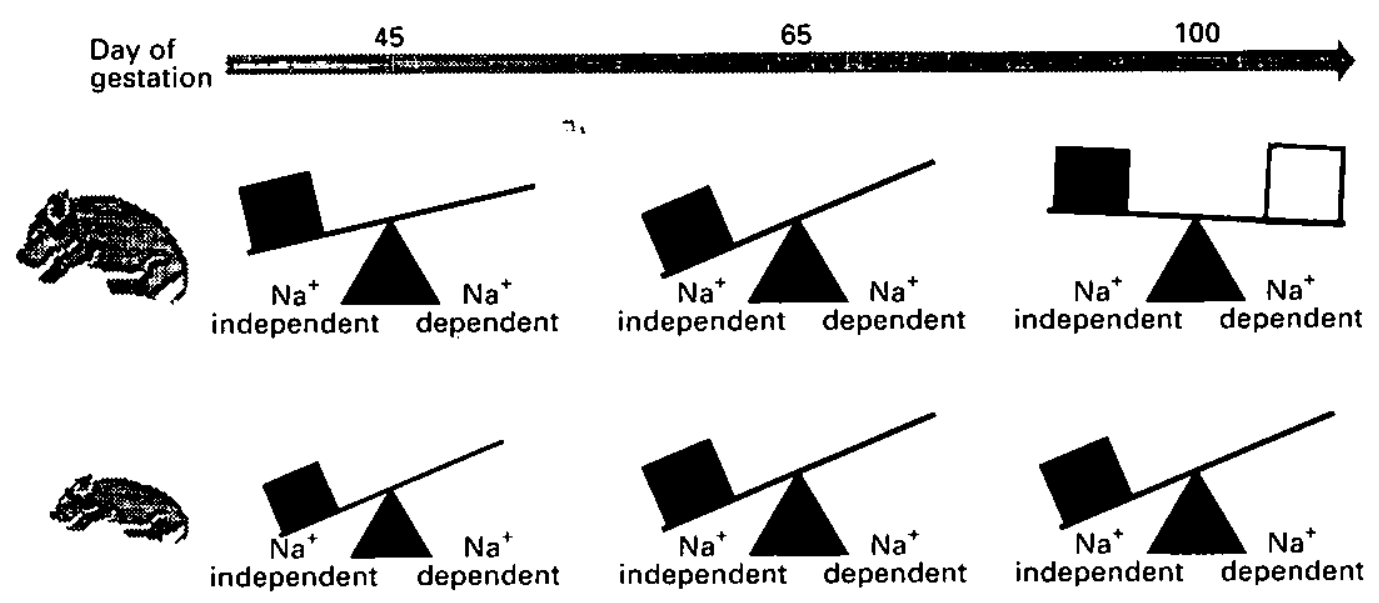

Fig. 5. Schematic diagram showing dif́erences in leucine transport characteristics of placentae supplying normally (upper line) and inadequately (lower line) grown pig fetuses at key stages of gestation.

cortisol concentrations on day 65 (M. Nwagwu, K. Page and C. J. Ashworth, unpublished). It is not clear whether these inverse relationships reflect size-related alterations in fetal adrenal

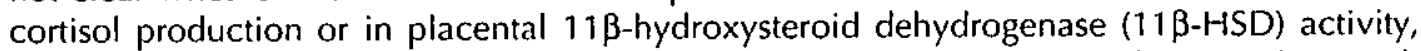
which normally protects the fetus from high circulating concentrations of maternal cortisol. However, Klemcke and Christenson (1996) found no convincing evidence for an association between pig fetal size and placental 11ß-HSD activity on days 50, 75 and 100 of pregnancy. A role for fetal pituitary hormones in fetal growth also appears unlikely, as decapitated pig fetuses grow and develop normally (Strkyer and Dziuk, 1975). Given that the fetal adrenal is the primary source of fetal plasma cortisol on days 50 and 100 (Klemcke, 1995), size-related differences in fetal cortisol concentrations are probably a function of differences in adrenal production or release perse.

The cause or effect nature of the relationship between cortisol concentrations and fetal size remains to be determined. In sheep fetuses, cortisol suppresses both IGF-I and IGF-II gene expression (for review see Fowden et al., 1998), indicating that high cortisol concentrations may themselves reduce the drive for fetal growth. Early activation of the fetal hypothalamic-pituitary-adrenal (HPA) axis is likely to promote a premature cortisol-induced switch from cell proliferation to differentiation, leading to inappropriate growth for the developmental stage of the conceptus.

There is a positive correlation between fetal plasma cholesterol concentrations and fetal weight on day 104 of pregnancy (Wise et al., 1997). The physiological significance of this observation is not clear, but may be related to the observation that brains from runt fetuses contain less cholesterol and, therefore, are less myelinated than the brains of normally grown littermates (Dickerson et al., 1971).

Temporal changes in placental expression of CSF-1 in the pig mirror the pattern of placental growth and development in this species (Tuo et al., 1995). Therefore, CSF has been proposed as an important regulator of placental development. Immunohistochemistry did not reveal a relationship between fetal size and localization of CSF-1 at the maternal-fetal interface; however, staining was more intense in endometrial and placental tissues supplying small fetuses compared with tissues surrounding normal sized fetuses (Ashworth et al., 1998a). The reasons for this intriguing observation are unclear, but it does highlight local sizedependent differences in the abundance of CSF-1. 


\section{Consequences of fetal growth retardation}

Low birthweight piglets are more likely to die from starvation (Hartsock et al., 1977) and thermoregulatory stress (Herpin and Le Dividich, 1995) than are their heavier littermates. The incidence of preweaning mortality is similar in light piglets which form part of a normally distributed population (SGA) and in those which are statistical outliers (IUGR) (van der Lende and de Jager, 1991). Low birthweight piglets that do survive grow more slowly, have reduced feed conversion efficiencies (Powell and Aberle, 1980) and reach a lower mature body weight (Widdowson, 1971) with a higher body fat to muscle ratio (Powell and Aberle, 1980) than do normally grown piglets. In addition, low birthweight piglets show compromised muscle (Bauer et al., 2000a), cardiac and renal (Bauer et al., 2000b) physiology. Cross-fostering runt piglets to a less competitive environment does little to improve these problems, indicating that there may be limited scope after birth to improve the consequences of prenatal growth restriction.

The ratio between piglet birth weight and the mass of its placenta does not affect subsequent weaning weight, growth rate or backfat depth (Biensen et al., 1999b), indicating that fetal weight per se is the major determinant of subsequent performance.

\section{Neonatal growth and vigour}

Although runt piglets experience a period of compensatory growth during the first 2 weeks of life, they never achieve the same mature body weight as their littermates (Widdowson, 1971). In addition, internal organs, including the liver, remain disproportionately small throughout the first 3 years. Feeding runt piglets with milk replacer to either mimic the intake a runt piglet would receive if left on the sow or to mimic an unrestricted intake from days 3 to 14 did not affect growth rate (Ritacco et al., 1997). These data indicate that growth-retarded piglets have a reduced absorptive capacity or altered postabsorptive metabolism. A reduced absorptive capacity appears unlikely, as the runt piglets consuming more milk replacer had an increased liver mass (Ritacco et al., 1997) and because IUGR is associated with the precocious occurrence of maltase and sucrase activities in the mucosa of the small intestine (Xu et al., 1994).

Low birthweight pigs take longer to suckle (Tuchscherer et al., 2000), indicating a possible compromise of behavioural development affecting subsequent neonatal vigour. This finding may explain why low birthweight piglets have lower circulating concentrations of IgC than do their heavier littermates (Antipatis et al., 2001).

As a consequence of the brain sparing associated with intrauterine growth retardation, a higher proportion of the weight of the runt piglet is represented by brain tissue. However, the brains of runt piglets are more poorly developed than those of normally grown siblings, with less myelination and dendritic development (Dickerson et al., 1971).

\section{Muscle biology}

Low birth weight in pigs is associated with a reduced total number of muscle fibres (Handel and Stickland, 1987a). Although the number of muscle fibres and the ratio between primary and secondary fibres are sensitive to nutrition during pregnancy (Dwyer et al., 1994), muscle fibre hyperplasia is complete by day 90 of gestation (Wigmore and Stickland, 1983). Therefore, the alterations in fibre number observed at birth are permanent. Except in very extreme cases of runting, reduced total number of muscle fibres is generated through a reduction in the ratio between secondary and primary fibres (Handel and Stickland, 1987a). More detailed investigation of the muscle fibre types affected by runting revealed that 
postnatal differentiation of muscle fibres was related more to physiological maturity (weight) than to chronological age (Handel and Stickland, 1987b). At equivalent live weights, the area of the semitendinosus muscle occupied by slow-twitch, oxidative metabolism fibres was greater in low birthweight piglets compared with normal sized littermates. The net effect of these observations is that animals developing from low birthweight piglets contain more slow muscle fibres than do littermates that were heavier at birth. In keeping with the greater prevalence of slow fibres, muscle blood flow and contractile function are more developed and calf muscles appear more tolerant to fatigue in newborn growth-retarded pigs (Bauer et al., 2000a).

Thyroid hormones play a major role in muscle development and function. In particular, nuclear thyroid hormone receptors (TR) are important in fetal myogenesis and the ratio of $\operatorname{TR} \alpha 1: \operatorname{TR} \alpha 2$ receptor isoforms is believed to determine muscle type. In pigs, intrauterine growth retardation is associated with reduction in the number of skeletal muscle TRs (Dauncey and Geers, 1990) and a 50\% downregulation of TR $\alpha 1$ expression in pig cardiac muscle (Dauncey et al., 2001). Low cardiac muscle TR $\alpha 1$, combined with a reduction in plasma thyroid hormone concentrations, would reduce cardiac $\alpha$-myosin transcription, which, in turn, would be expected to lead to a lower intrinsic contractile ability and operational heart rate. However, Bauer et al. (2000b) reported that heart rate, cardiac output, arterial blood gases and $\mathrm{pH}$ were similar in normal weight and IUGR piglets, although arterial blood pressure and glucose content were significantly lower.

Accompanying the changes in muscle fibre number and type associated with low piglet birth weights are increases in body fat. At equivalent live weight (96-109 kg), pigs that were light at birth had more adipocytes in the perirenal tissue and subcutaneous depot compared with their heavier birthweight siblings (Powell and Aberle, 1981).

\section{Neonatal adrenal function}

Plasma cortisol concentrations are related inversely to piglet weight on the day of birth (Wise et al., 1991) and on days 3 and 7 after birth (Klemcke et al., 1993). Inverse relationships between piglet weight and both adrenal weight and responsiveness of adrenal cells to ACTH in vitro are also evident on days 3 and 7 (Klemcke et al., 1993). Differences in the sensitivity of the HPA axis are thought to originate during prenatal life and to be mediated by alterations in glucocorticoid receptor gene expression in the fetal hippocampus, which is involved in the feedback control of the HPA axis. Recent studies in rats have indicated that prenatal alterations in the sensitivity of the HPA axis may affect the subsequent stress responses of the individual (Welberg et al., 2000).

In neonates, cortisol serves an essential physiological role, including glucose homeostasis and adaptation to enteric nutrition. Although increased neonatal cortisol concentrations may be associated with short-term advantage, in humans and rodent species increased neonatal glucocorticoid concentrations have been linked with hypertension and impaired glucose tolerance in adult life. Indeed, high neonatal glucocorticoid concentrations are thought to be central in explaining epidemiological relationships between low birth weight and later cardiovascular problems. However, such relationships have not yet been studied in domestic species.

\section{Conclusion}

In pigs, approximately one-third of litters contain at least one piglet that is substantially lighter than its littermates. The variability in fetal size with in a litter appears to be established during the first month of pregnancy. Furthermore, the prevalence of inadequately grown pig fetuses is 
as great on day 30 of pregnancy as at term. Therefore, limited uterine space does not appear to be a primary determinant of inadequate fetal growth. Instead, the efficacy of placental attachment, coupled with the subsequent ability of that placenta to supply the developing fetus with nutrients, appears to be critical to ensure appropriate fetal growth.

Inadequate growth during intrauterine life has a detrimental effect on a diverse range of physiological functions in the offspring, many of which persist throughout life. There are limited opportunities to remedy the postnatal consequences of intrauterine growth retardation. Therefore, attempts to alleviate inadequate fetal growth in pigs should focus on opportunities to promote within-litter uniformity throughout pregnancy.

Unpublished results from the authors' laboratories were produced with iunding from the Scottish Executive, Rural Affairs Department.

\section{References}

Antipatis C, Rooke JA, Ewen M and Ashworth CJ (2001) Both moderate vitamin A deficiency during pregnancy and birthweight affect piglel immunity Proceedings of the Nutrition Society 6072 (Abstract)

Ashworth CJ (1991) Elffect of pre-mating nutritional slatus and post-mating progesterone supplementation on embryo survival and conceptus growth in gilts Animal Reproduction Science 26 311-321

Ashworth CJ and McArdle HJ (1999) Both placental amino acid uptake and fetal plasma amino acid concentrations differ between small and normally-grown porcine fetuses Early Human Development 54 90-91

Ashworth C), Haley CS, Aitken RP and Wilmut I (1990) Embryo survival and conceptus growth after reciprocal embryo transier between Chincse Meishan and Landrace $\times$ Large White gilts Journal of Reproduction and Fertility 90 595-603

Ashworth Cl, Cagney C, Hoggard N and Lea RG (1998a) Effect of breed and fetal size on porcine placental histology and immunolocalisation of leptin and CSF-1 Journal of Reproduction and Fertility Abstract Series 22 56 (Abstract)

Ashworth CJ, Beattie L, Duthie SJ and McArdle HJ (1998b) Breed differences in mitogenic potential of porcine allantoic fluid Biology of Reproduction 58 (Supplement 1) 217

Bauer R, Walter B, Hoppe A, Gaser E, Lampe V, Kauf E and Zweiner $U$ (1998) Body weight distribution and organ size in newborn swine (Sus scrofa domestica) - a sludy describing an animal model for asymmetrical intrauterine growth retardation Experimental Toxicology and Pathology 50 59-65

Bauer R, Wank V, Walter B, Blickhan $R$ and Zweiner $U$ (2000a) Reduced muscle vascular resistance in intrauterine growth restricted newborn pigiets Experimental Toxicology and Pathology 52 271-276

Bauer R, Walter B, lhring $W$, Kluge $H$, Lampe $V$ and Zweiner (2000b) Altered renal function in growthrestricled newborn piglets Pediatric Nephrology 14 735-739

Biensen NJ, Wilson ME and Ford SP (1999a) The impacts of uterine environment and fetal genotype on conceplus size and placental vascularity during late gestation in pigs Journal of Animal Science 77 954-959
Biensen NJ, Haussmann MF, Lay DC, Christian LL. and Ford SP (1999b) The relationship between placental and piglet birth weights and growth traits Animal Science 68 709-715

Christenson RK, Leymaster KA and Young LD (1987) Justification of unilateral hysterectomy-ovariectomy as a model to evaluate uterine capacity in sivine fournal of Animal Science 65 738-744

Cooper JE, John M, McFadyen IR and Wootton R (1978) Early appearance of 'runting' in piglets Veterinary Record 102 529-530

Dauncey MJ and Geers R (1990) Nuclear 3,5,3'triodothyronine receptors in skeletal muscle of normal and small-for-gestational age newborn piglets Biology of the Neonate 58 291-295

Dauncey MJ, White P, Burton KA and Katsumata M (2001) Nutrition-hormone receptor-gene interactions: implications for development and disease Proceedings of the Nutrition Society 60 63-72

Da Silva PFN, Finch AM, Antipatis C and Ashworth CJ (2000) Changes in the relationship between porcine fetal size and organ development during pregnancy Proceedings of the British Society of Animal Science 123 (Abstract 24)

Deves $R$ and Boyd CA (2000) Surface antigen CD98(4F2): nol a single membrane protein, but a family of proteins with multiple functions fournal of Membrane Biology 173 165-177

Dickerson JWT, Merat A and Widdowson EM (1971) Intrauterine growth retardation in the pig. III. The chemical structure of the brain Biology of the Neonate 19 354-362

Dwyer CM, Stickland NC and Fletcher JM (1994) The influence of maternal nutrition on muscle fiber number development in the porcine fetus and on subsequent post natal growth Journal of Animal Science 72 911-917

Dziuk P (1985) Effect of migration, distribution and spacing of pig embryos on pregnancy and fetal survival journal of Reproduction and Fertility Supplement 33 57-63

Finch AM, Zuur G and Ashworth Cl (1999) Differential growth of porcine fetuses: timing of IUGR Early Human Development 55 185-186

Finch AM, Ashworth CJ, Page KR and McArdle HJ (2000) 
Gestational changes in leucine transport across porcine placentas supplying littermates of differenı sizes journal of Physiology 528P 26P

Ford SP (1997) Embryonic and felal development in different genotypes in pigs Journal of Reproduction and Fertility Supp/ement 52 165-176

Fowden AL, Li / and Forhead AJ (1998) Glucocorticoids and the preparation for life after birth: are there longterm consequences of the life insurance? Proceedings of the Nutrition Society 57 113-122

Handel SE and Stickland NC (1987a) Muscle cellularity and birthweight Animal Production 44 311-317

Handel SE and Stickland NC (1987b) The growith and differentiation of porcine skeletal muscle fibre types and the influence of birthweight Journal of Anatomy 152 107-119

Harper AF, Lindemann MD and Konegay ET (1996) Fetal survival and conceplus development after 42 days of gestation in gilts and sows in response to folic acid supplementation Canadian Journal of Animal Science 76 157-160

Hartsock TG, Graves HB and Baumgardt BR (1977) Agonistic behaviour and the nursing order in suckling piglets fournal of Animal Science 44 320-330

Herpin P and Le Dividich J (1995) Thermoregulation and the environment. In The Neonatal Pig, Development and Survival pp 57-95 Ed. MA Varley. CAB International, Oxford

Kampman KA, Ramsay TG and White ME (1993) Developmental changes in hepatic IGF-2 and ICFBP.2 mRNA levcls in intrauterine growth-retarded and control swine Comparative Biochemistry and Physiology B 104 415-421

Klemcke HG (1995) Placental metabolism of cortisol at mid- and late gestation in swine Biology of Reproduction 53 1293-1301

Klemcke HG and Christenson RK (1996) Porcine placental 11ß-hydroxysteroid dehydrogenase activity Biology of Reproduction 55 217-223

Klemcke HC, Lunstra DD, Brown-Borg HM, Borg KE and Christenson RK (1993) Association between low birth weight and increased adrenocortical function in neonatal pigs fournal of Animal Science 71 1010-1018

Knight JW, Bazer FW, Thatcher WW, Franke DE and Wallace HD (1977) Conceptus development in intact and unilaterally hysterectomised-ovariectomised gilts: interrelationships among hormonal status, placental development, fetal fluids and fetal growth fournal of Animal Science 44 620-637

Lee $G$ ) and Maley CS (1995) Comparative farrowing to weaning performance in Meishan and Large White pigs and their crosses Animal Science 60 269-280

Nwagwu MO, Owens PC, Page KR and Ashworth C) (2000) Effect of breed and fetal size on day 100 porcine fetal hormone concentrations Journal of Reproduction and Fertility Abstract Series 2518 (Abstract)

Pere M-C, Dourmad J-Y and Etienne $M$ (1997) Effect of number of pig embryos in the uterus on their survival and development and on maternal metabolism fournal of Animal Science 75 1337-1342

Perry IS and Rowell JC (1969) Variations in felal weight and vascular supply along the uterine horn of the pig fournal of Reproduction and Fertility $19527-534$

Powell SE and Aberle D (1980) Effects of birth weight on growth and carcass composition of swine Journal of Animal Science 50 860-868

Powell SE and Aberle D (1981) Skeletal muscle and adipose tissue cellularity in runt and normal birth weight swine journal of Animal Science 52 748-756

Ritacco G, Radecki SV and Schoknecht PA (1997) Compensatory growth in runt pigs is not mediated by insulin-like growth factor I fournal of Animal Science 75 1237-1243

Ross JC, Fennessey PV, Wilkening RB, Battaglia FC and Meschia $G$ (1996) Placental transport and fetal utilization of leucine in a model of fetal growth retardation American Journal of Physiology 270 (Endocrinology and Metabolism 33) E491-E503

Royston J, Flecknell PA and Wooton R (1982) New evidence that the intra-uterine growth-retarded piglet is a member of a discrete subpopulation Biology of the Neonate 42 100-104

Schoknecht PA, Pond WG, Mersmann HJ and Maurer RR (1993) Protein restriction during pregnancy affects postnatal growth in swine progeny fournal of Nutrition 123 1818-1825

Schoknecht PA, Newton GR, Weise DE and Pond WG (1994) Protein restriction in early pregnancy alters fetal and placental growth and allantoic fluid proteins in swine Theriogenology 42 217-226

Sibley Cl, Glazier J and D'Souza S (1997) Placental transporter activity and expression in relation to felal growth Experimental Physiology 82 389-402

Stryker JL and Dziuk PJ (1975) Effects of fetal decapitation on fetal development, parturition and lactation in pigs Journal of Animal Science 40 282-287

Tuchscherer, Puppe B, Tuchscherer A and Tiemann $U$ (2000) Early identification of neonates at risk: traits of newborn piglets with respect to survival Theriogenology 54 371-388

Tuo W, Harney JP and Bazer FW (1995) Colony-stimulating factor- 1 in conceptus and uterine lissues in pigs Biology of Reproduction 53 133-142

van der Lende $T$ and de Jager $D$ (1991) Death risk and preweaning growth rate of piglets in relation to the within-litter weight distribution at birth Livestock Production Science 28 73-84

van der Lende T, Hazeleger $W$ and de Jager D (1990) Weight distribution within litters at the early foetal stage and at birth in relation to embryonic mortality in the pig Livestock Production Science 26 53-65

vom Saal FS, Quandagno DM, Even MD, Keisler LW, Keisler DH and Khan S (1990) Paradoxical effects of maternal stress on fetal steroids and postnalal reproductive traits in female mice from different intrauterine positions Biology of Reproduction $43751-761$

Wetberg LA, SeckI JR and Holmes MC (2000) Inhibition of 11 beta-hydroxysteroid dehydrogenase, the íeto-placental barrier to maternal glucoconticoids, permanently programs amygdala CR mRNA expression and anxiety-like behaviour in the offspring European fournal of Neuroscience 12 1047-1054 
Widdowson EM (1971) Intra-uterine growth retardation in the pig. I. Organ size and cellular development at birth and after growth to maturity Biology of the Neonate 19 329-340

Wigmore PM and Stickland NC (1983) Muscle development in large and small pig fetuses fournal of Anatomy 137 235-245

Winters LM, Cummings JN and Stewart HA (1947) A study of factors affecting survival from birth to weaning and total weaning weight of the litter of swine fournal of Animal Science 6 288-296

Wise T and Christenson RK (1992) Relationship of fetal position within the uterus to fetal weight, placental ' weight, testosterone, estrogens and thymosin $\beta 4$ concentrations at 70 and 104 days of gestation in swine fournal of Animal Science 70 2787-2793

Wise T, Stone RT and Vernon MW (1991) Relationships of serum estriol, cortisol and albumin concentrations with pig weight at 110 days of gestation and at birth Biology of the Neonate 59 114-119

Wise T, Roberts AJ and Christenson RK (1997) Relationships of light and heavy fetuses to uterine position, placental weight, gestational age and fetal cholesterol concentrations Journal of Animal Science 75 2197-2204

Wootton R, McFadyen IR and Cooper JE (1977) Measurement of placental blood flow in the pig and its relation to placental and fetal weight Biology of the Neonate 31 333-339

Wu MC, Chen ZY, Jarrell VL and Dziuk PJ (1989) Effect of initial length of uterus per embryo on fetal survival and development in the pig Journal of Animal Science 67 1767-1772

Wu G, Pond WG, Ott T and Bazer FW (1998) Maternal dietary protein deficiency decreases amino acid concentration in fetal plasma and allantoic fluid of pigs Journal of Nutrition 128 894-902

Xu RJ, Mellor DJ, Birtles MJ, Reynolds GW and Simpson HV (1994) Impact of intrauterine growth retardation on the gastrointestinal tract and the pancreas in newborn pigs Journal of Pediatric Gastroenterology and Nutrition 18 231-240

Young LG, King G), Walton IS, McMillan I, Klevorick M and Shaw L (1990) Gestation energy and reproduction in sows over four parities Canadian Journal of Animal Science 70 493-506 